\section{VERBALIZATION OF THE CONCEPT AIRCRAFT \\ IN THE NOVEL “AIRPORT” BY A. HAILEY: \\ COGNITIVE AND SEMANTIC CHARACTERISTICS}

\section{A. Posokhova ${ }^{1}$}

DOI: http://doi.org/10.15350/L_26/8/05

\title{
Abstract
}

The article deals with the research of the cognitive and semantic characteristics of the verbalization of the concept AIRCRAFT in the novel "Airport" by A. Hailey. The concept is analyzed as a component of the cognitive model of the content of the text concept of the novel. The terminological and professional lexis function as productive means of actualization of the specific professional environment.

Keywords: professional novel, concept, frame, cognitive sign, cognitive model.

Исследование когнитивно-семантических особенностей организации концептуального пространства романа А. Хейли„Аэропорт” на примере вербализации концепта AIRCRAFT направлено на определение места этого концепта в общей модели содержания текстового концепта, изучение особенностей его презентации в тематической структуре романа и анализ вербальной базы актуализации данного концепта.

Изучение особенностей вербализации концепта обуславливает необходимость определения содержания концепта. Исследованию концепта посвящены работы В.З. Демьянкова, В.И. Карасика, Е.С. Кубряковой [3-5]. 3.Д. Попова и И.А. Стернин рассматривают концепт как полевую структуру, состоящую из ядра, приядерной сферы, которая включает концептуальные признаки (концептуальные слои), и периферию [6, с. 64].

Другой когнитивной структурой, которая активно используется при проведении лингвокогнитивных исследований, является фрейм. М. Минский квалифицирует фрейм как структуру данных для представления стереотипной ситуации, презентуя ее в виде некой последовательности вопросов, ответы на которые помогают интерпретировать гипотетическую ситуацию [8, с. 360]. Т.А. ван Дейк рассматривает фреймы как стереотипные ситуации (интеракции), определяющие поступки участников, действующих в очерченных рамках социальных установок [7, с. 27]. По мнению Н.Н. Болдырева фрейм - это,объемный, многокомпонентный концепт, представляющий собой,пакет” информации, знания о стереотипной

${ }^{1}$ Anzhela Posokhova, Senior Lecturer, Lviv State University of Internal Affairs, Ukraine. 
ситуации" [2, с. 36]. Ученый подчеркивает связь между этими двумя когнитивными структурами, отмечая, что фрейм используется для,,обозначения структурированных концептов; он входит в состав концепта, который, в свою очередь, используется для представления любых единиц знания, в том числе неструктурированных" [1, с. 29].

Возьмем за основу эти определения, внеся некоторые изменения с учетом нашего предмета исследования: фреймы в концептуальном пространстве профессиональной коммуникации функционируют как стереотипные ситуации, развитие которых существенно регламентируется требованиями конкретной сферы профессиональной деятельности относительно развития типичных рабочих ситуаций и служебных отношений. Фреймы, в свою очередь, регламентируют поступки субъектов этой профессиональной среды, которые действуют в рамках своей служебной компетенции и на основании четко очерченных служебных правил и инструкций.

Зависимость функциональной активности фрейма от требований институциональной среды влияет на фрейм, превращая его в некой степени в статичную ментальную единицу. Однако, несмотря на свою детерминированность требованиями служебного окружения, каждая типичная ситуация имеет множество непредусмотренных вариантов своего развития, которые обусловлены действием субъективных факторов, а значит, возникает необходимость введения ментальной единицы, структурирующей развитие ситуации и отличающейся от фрейма динамичностью функционирования. Такая динамичная ментальная единица определяет типичную служебную/профессиональную ситуацию, т.е. отличается тематической принадлежностью к определенной служебной/профессиональной процедуре, что дает основание обозначить ее термином топик. Поэтому, при изучении концептуального пространства профессионального романа, которое определяет семантику профессионального контекста произведения, мы рассматриваем фрейм как типичную служебную ситуацию, а топик как концептуальную единицу развития такой ситуации.

Целью исследования является изучение особенностей вербализации концепта AIRCRAFT в литературно-художественном дискурсе, предметом исследования являются когнитивно-семантические аспекты вербализации концепта AIRCRAFT, объектом изучения является номинативное поле концепта AIRCRAFT в тексте романа А. Хейли,Аэропорт”.

Содержание текстового концепта AIRPORT отличается иерархичностью своей организации и состоит из ядра (базового концепта - в нашем случае это и текстовый концепт), приядерной зоны, включающей производные концепты 1 уровня, ближней периферии с производными концептами 2 уровня, дальней периферии с производными концептами 3 уровня и крайней периферии или зоны смежных концептов. На основе анализа словарных дефиниций нами были определены параметры информационного содержания понятия “airport” и на этой основе определены ключевые когнитивные признаки. Выявленные когнитивные признаки, формирую- 
щие содержание концепта AIRPORT, легли в основу исходной модели содержания концепта. Производный концепт AIRCRAFT, который является предметом исследования в данной статье, вошел в состав приядерной зоны, наряду с другими концептами первого уровня, такими как: AREAS, SAFETY, CARGO, PASSENGERS, AIRCREW, AUTHORITIES, OPERATIONS \& SERVICES, ATC TOWER, BUILDINGS. Рассмотрим роль концепта AIRCRAFT в структуре содержания концепта AIRPORT и проанализируем вербальную базу его объективации.

Концепт AIRCRAFT детализирует виды авиационной техники, номинативное поле этого концепта включает как терминологические единицы, которые представляют авиационный парк - aircraft; airplane; jet, так и терминологические единицы, которые называют отдельные элементы корпуса самолета - fuselage; tail. Часто этот концепт экспликуется на уровне названия типа самолета: a Boeing 707. Характерно употребление ономастических единиц- названий авиалиний, которые являются элементами названий самолетов этих компаний: an Aéreo-Mexican jet. В центре внимания героев романа самолет Мексиканских авиалиний, который заблокировал взлетно-посадочную полосу: an Aéreo-Mexican jet -- a Boeing 707 = > Aéreo-Mexican 707 => Aéreo-Mexican (its fuselage and tail blocking runway three zero) => the big jet. Первым когнитивным признаком является принадлежность к определенной авиалинии (Aéreo-Mexican - сохраняется оригинальное написание названия), вторым - тип/модель самолета (Boeing 707). В дальнейшем описании событий обе характеристики соединяются и употребляются в комбинированном или сокращенном варианте (AéreoMexican 707); дальнейшая номинация в тексте сопровождается развернутым уточнением, которое проясняет причину аварийной ситуации на взлетно-посадочной полосе 30 (its fuselage and tail blocking runway three zero); следующее упоминание резюмирует причины аварийной ситуации: the big jet, то есть слишком большой и сложный объект, который необходимо устранить, не повредив ни сам самолет, ни взлетно-посадочную полосу.

Таким образом, лексическая база, объективирующая концепт AIRCRAFT в романе А. Хейли, отличается разноплановостью. Для обозначения авиапарка самолетов в тексте романа часто употребляется ономастическая лексика: 1) названия самолетов, включающие имена владельца: Aéreo-Mexican, указано название авиакомпании, которой принадлежит самолет; U.S. Air Force KC-135 - название самолета безошибочно идентифицирует его как военный самолет, поскольку есть номинация ВВС CША (U.S. Air Force); 2) названия самолетов, включающие название его модели - Boеing 707; 3) названия самолетов с маркировкой модели на основе цифр и букв: the civil version of the $\boldsymbol{C}-\mathbf{5 A}$ (пассажирский самолет, который есть версией военного самолета); the $747 s$; the old $842 ; 4)$ названия самолетов, включающие качественные характеристики: Boeing 707-320B Intercontinental Jetliner, модификация Боинга 707, о чем свидетельствует дополнительная маркировка (320B), также это реактивный самолет для 
межконтинентальных перелетов (Intercontinental Jetliner); 5) названия самолетов, включающие названия авиарейсов: Boeing 707 aircraft which was now Flight Two; first-class section of Flight Two - в последнем примере название рейса полностью замещает название самолета; 6) каждый самолет имеет свой кодовый номер, под которым значится во всех бортовых документах, в документации аэропорта, авиакомпаний, международных организаций, что контролируют авиаперевозки: Boeing 707-N-731-TA, certified $\boldsymbol{N - 7 3 1 - T A}$ as completely airworthy, the wing tanks of $\mathbf{N - 7 3 1 - T A ~ - ~ п р и в е д е н н ы е ~}$ названия самолета иллюстрируют использование регистрационного/ кодового номера (registered number N-731-TA) как в функции отдельного элемента расширенного названия, так и в функции названия самолета.

Другая группа лексических единиц, вербализирующих концепт AIRCRAFT, охватывает обозначения на основе лексем aircraft, airplane, jet и supersonic: 1) лексические единицы на основе существительного aircraft: существительное aircraft в функции подлежащего: aircraft is balanced, and stable in the air; aircraft will be available on time; on the airfield tonight, all aircraft were being subjected to long delays, with engines running, before takeoff; cyществительное aircraft и притяжательная форма существительного aircraft в функции определения: aircraft mechanics, aircraft taking off, aircraft's passengers, aircraft's range at maximum weight; существительное aircraft в составе предложных словосочетаний: for aircraft use; complain about noise from aircraft overhead; steady stream of aircraft was taking off and landing; cyществительное aircraft с описательными и квалифицирующими определениями: waiting aircraft, the hundred and twenty ton aircraft, particular airplane, substitute aircraft; 2) лексические единицы на основе существительного airplane: существительное airplane в функции подлежащего: airplane functions well, operational flights of airplanes; существительное airplane в функции дополнения: certify the airplane as completely airworthy, observe an airplane taxiing in, want the airplanes to stop coming over; существительное airplane с описательным определением: big airplanes; 3) лексические единицы на основе существительного jet: производные существительные на основе лексемы jet: jet plane, jetliner; существительные jet и jet plane в функции определения: jet takeoffs and landings, jet plane fuselage, jet engine; существительные jet и jet plane в функции подлежащего: jets, jet plane, when the jets first started flying; существительное jet в сочетании с определением: multimillion dollar jets, the big jet, get the big jet moved; 4) лексическая единица на основе существительных jet и supersonic: mammoth jets and supersonics. Последние две подгруппы лексических единиц образованы на основе существительных, которые означают класс самолета: jet - реактивный самолет и supersonic - сверхзвуковой самолет.

Третья группа лексических единиц, вербализирующих концепт AIRCRAFT, включает лексические номинации частей самолета на основе лексем engine, fuselage, tail, wheels, motor и словосочетаний, образованных на их основе: the aircraft's electrical system; a stainless steel pipe around the affected engine; engine overheated, start engines; operate with three engines; immediate procedure for the engine; keep the motor running for warmth. 
В связи с тем, что в романе поднимается тема организации пассажирских и грузовых авиаперевозок, для дифференциации разных типов самолетов, предназначенных для различных видов авиаперевозок, употребляются соответствующие квалифицирующие термины: 1) для обозначения самолетов для грузовых перевозок употребляются терминологические словосочетания - freight aircraft, all-cargo aircraft, jet freighter; 2) для обозначения пассажирских самолетов используются терминологические словосочетания - passenger aircraft, passenger jets, passenger airliners. В этих терминах квалификаторами предназначения самолета выступают лексемы freight, cargo, passenger, например: Unlike conventional passenger planes, the inside of a jet freighter was usually a hollow shell.

Тенденция номинации субъекта коммерческой деятельности является характерной особенностью деловой коммуникации, что находит соответствующее отражение при указании на названия авиакомпаний в тексте романа - Trans America Airlines, Trans America and other airlines, British Overseas Airways Corporation. В основе языковых средств, называющих авиакомпании, в большинстве случаев лежит лексема airline / airlines (реже встречаются номинации на основе лексемы сотраny).

Авиакомпании являются субъектами коммерческой деятельности, которую они ведут, предоставляя услуги авиаперевозок через систему аэропортов. Таким образом, в каждом аэропорту есть представительство компании: the Trans America base - представительство компании Trans America в аэропорту Lincoln International. Соответственно, они имеют свой парк самолетов, свои офисы в аэропортах, свою систему менеджмента, свой штат работников разного ранга, свои структурные подразделения и службы:

1) the BOAC airliner Trans America (a switch of mail from the BOAC airliner Trans America) - самолет авиакомпании Trans America; Trans America Airline Flight Two - The Golden Argosy, Trans America Flight Two - название рейса, что осуществляется авиакомпанией Trans America, также это название часто употребляется для номинации самолета, что совершает этот перелет;

2) the Trans America base maintenance - отдел материально-технического обеспечения и ремонтных работ компании Trans America; the Trans America base maintenance chief - начальник отдела материально-технического обеспечения и ремонтных работ компании Trans America;

3) the company weather forecaster - синоптик, который ведет наблюдения за изменениями погоды и составляет синоптические графики и рекомендации, которые включаются в планы полетов: airline weather forecasts and flight plans;

4) airline baggage systems - система обеспечения контроля и перевозки багажа пассажиров, т.к. ответственность за сохранность и доставку багажа несет авиакомпания, рейсами которой летят пассажиры, airlines employ staffs, at every major terminal, whose job is solely to trace missing baggage - компания формирует штат своих работников, заданием которых является отслеживание и возвращение утерянного багажа. 
Отдельную группу работников компании составляет летный состав, например: 1) the chief Trans America pilot at the base - руководитель летного состава в представительстве компании Trans America в аэропорту, про его высокий ранг говорить и другой вариант названия его должности в административной иерархии компании: the executive pilot; 2) a four-striper Trans America captain - капитан компании Trans America, летчик высшего ранга (о чем свидетельствуют 4 шеврона); 3) the Captain Vernon Demerest of Trans America - капитан компании Trans America Vernon Demerest - один из главных героев романа.

Тема авиапарка в романе неразрывно связана с темой подготовки самолета к полету, проведением полета и посадкой авиалайнера. Проанализируем развитие в романе темы подготовки самолета к полету. Фрейм PREPARATION FOR THE FLIGHT / ПОДГОTOВКА К ПОЛЕТУ разворачивается в романе как последовательный сценарий:

(1) complicated operation on the replacement of the overheated engine and all one hundred and eight pairs of wires to pursue the high safety standards $=>$ (2) test fly $=>$ (3) certification for the flight as completely airworthy => (4) taxing to the terminal gate $=>$ (5) Departure Control orders food for the flight, according to the number of passengers expected => (6) the food and liquor go aboard => (7) liquor stocks come aboard => (8) commissary supplies are checked and replenished => (9) baggage is coming aboard Flight Two as passengers are beginning to check in $=>$ (10) freight and mail go aboard Flight Two => (11) an extra two thousand pounds of fuel are added for taxiing and ground running in addition to the normal reserve for that purpose $=>$ (12) in the crew room captains inspect mail for the company bulletins which must be read before the flight $=>$ (13) the crew bus takes the crew from the hangar to the terminal => (14) the stewardesses go off to complete their preflight procedures $=>(15)$ in the Trans America international dispatch office the pilots study a folder with the information on airways, airport conditions, and weather prepared by the dispatcher => (16) The boarding is delayed by the Departure Control to give extra time for the passengers who are late $=>$ (17) Flight Two is announced, the boarding starts.

Сценарий подготовки самолета к вылету, который лежит в основе развития сюжетной линии романа, максимально приближен к типичной служебной ситуации. Писатель, хорошо знакомый со спецификой работы аэропорта, дает детальное описание процесса подготовки самолета к роковому вылету в Рим. Скрупулезное описание сложной процедуры с использованием преимущественно терминологической и профессиональной лексики сферы авиаперевозок дополнено включением интересных реалий этой профессиональной сферы, что также способствует созданию профессионально достоверной картины художественного мира романа.

Таким образом, многокомпонентная структура организации деятельности авиакомпаний, которые работают на территории аэропорта, нашла свое отражение в тексте романа А. Хейли,Аэропорт”. Проведенный анализ дал возможность уточнить структуру содержания текстового концепта романа и ввести в приядерную зону базового концепта AIRPORT новый производный концепт первого уровня AIRLINES. Поскольку концепт 
AIRCRAFT является производным от концепта AIRLINES, он в уточненной модели содержания текстового концепта AIRPORT получает статус производного концепта второго уровня, а производные от него концепты PASSENGER AIRCRAFT та FRIGHT AIRCRAFT функционируют в полевой структуре содержания концепта как концепты третьего уровня. Лексическая база романа является профессионально детерминированной, терминологическая и профессиональная лексика функционируют в тексте романа как продуктивные вербальные средства объективации сложного концептуального пространства профессиональной среды, воссозданной на страницах профессионального романа.

\section{References:}

[1] Болдырев Н.Н. Концептуальное пространство когнитивной лингвистики / Н.Н. Болдырев // Вопросы когнитивной лингвистики. 2004. № 1. С. 18-36.

[2] Болдырев Н.Н. Концепт и значение слова / Н.Н. Болдырев // Методологические проблемы когнитивной лингвистики / Ред. И.А. Стернин. Воронеж: Воронежский государственный университет, 2001. С. 25-36.

[3] Демьянков В.3. Понятие и концепт в художественной литературе и научном языке / В.3. Демьянков // Вопросы филологии. 2001. № 1. С. 35-47.

[4] Карасик В.И. Языковой круг: личность, концепты, дискурс: монография / В.И. Карасик. М.: Гнозис, 2004. 390 с.

[5] Краткий словарь когнитивных терминов / Е.С. Кубрякова, В.З. Демьянков, Ю.Г. Панкрац, Н.Г. Лузина / Ред. Е.С. Кубрякова. М.: Изд-во МГУ, 1997. 246 с.

[6] Попова З.Д., Стернин И.А. Очерки по когнитивной лингвистике / З.Д Попова, И.А. Стернин. Воронеж: Изд-во «Истоки», 2003. 191 с.

[7] Dijk T.A., van. Semantic Macrostructures and Knowledge Frames in Discourse Comprehension / T.A., van. Dijk // Cognitive Processes in Comprehension; Just M.A., Carpenter P.A. Hillsdale, 1977. P. 3-32.

[8] Minsky M. Frame-System Theory / M. Minsky // Thinking; Johnson-Laird P., Wason P.C. Cambridge: Mass, 1977. P. 355-376.

[9] Hailey A. Airport. Toronto: Bantam Books of Canada Ltd., 1968. 10 $0^{\text {th }}$ print. $502 \mathrm{p}$. 